\title{
Intrapopulation Chromosomal Polymorphism in Mazama gouazoubira (Cetartiodactyla; Cervidae): The Emergence of a New Species?
}

\author{
Mirela P. Valeri lara M. Tomazella José M.B. Duarte \\ Núcleo de Pesquisa e Conservação de Cervídeos (NUPECCE), Departamento de Zootecnia, Faculdade de Ciências \\ Agrárias e Veterinárias, Universidade Estadual Paulista (UNESP), Jaboticabal, Brazil
}

\section{Keywords}

B chromosome · Centric fusion · G-banding · Gray brocket deer

\begin{abstract}
Mazama gouazoubira is a small deer species widely distributed in South America. Previous studies have shown that this species presents intraspecific chromosomal polymorphisms, which could affect fertility due to the effects of chromosomal rearrangements on gamete formation. Important aspects regarding the karyotype evolution of this species and the genus remain undefined due to the lack of information concerning the causes of this chromosomal variation. Nineteen individuals belonging to the Mazama gouazoubira population located in the Pantanal were cytogenetically evaluated. Among the individuals analyzed, 9 had $B$ chromosomes and 5 carried a heterozygous centric fusion $(2 n=69$ and $F N=70)$. In 3 individuals, the fusion occurred between chromosomes $X$ and 16, in 1 individual between chromosomes 7 and 21, and in another individual between chromosomes 4 and 16 . These striking polymorphisms could be explained by several hypotheses. One is that the chromosome rearrangements in this species are recent and not fixed in the population yet, and another hypothesis is that they represent a balanced polymorphism and that heterozygotes have an adaptive ad-
\end{abstract}

\section{KARGER}

(C) 2018 S. Karger AG, Basel

E-Mail karger@karger.com

www.karger.com/cgr vantage. On the other hand, these polymorphisms may negatively influence fertility and raise questions about sustainability or reproductive isolation of the population.

(c) 2018 S. Karger AG, Basel

Mazama gouazoubira, the gray or brown brocket deer, is a small deer species found from southern Uruguay to the north of the Mato Grosso state in Brazil and from the Andes to the Atlantic. Its habitat varies from closed Cerrado to agricultural areas. This species can readily adapt to modified areas due to its high ecological plasticity [ $\mathrm{Du}-$ arte, 2007; Rodrigues et al., 2014].

M. gouazoubira $(2 \mathrm{n}=70 ; \mathrm{FN}=70)$ has 68 acrocentric autosomes, an acrocentric X, and a metacentric Y [Neitzel, 1987; Fontana and Rubini, 1990], similar to the putative Cervidae ancestral karyotype [Dementyeva et al., 2010]. The karyotypes of other species in the Mazama genus differ from the proposed ancestral deer karyotype by a high number of chromosomal rearrangements, including tandem fusions, centric fusions, pericentric inversions, and the presence of B chromosomes [Fontana and Rubini, 1990].

Considerable intraspecific variation in the chromosome number exists in M. gouazoubira due to Robertsonian translocations and B chromosomes [Duarte, 1992, 
1998; Duarte and Jorge, 1996]. Some researchers hypothesize that this chromosome variability is due to chromosomal fragility, which promotes chromosomal breaks and rearrangements [Duarte, 1998; Vargas-Munar et al., 2010]. Robertsonian rearrangements (centromeric fissions and fusions) are the most commonly incorporated rearrangements in mammalian karyotype evolution. It is known that this type of rearrangement can lower fitness due to the production of unbalanced gametes [Baker and Bickham, 1986]. Therefore, it would be important to better understand Robertsonian rearrangements due to their frequent occurrence in evolution and their influence on fertility [Daniel, 1988; Ferlin et al., 2006]. Further, the mechanism about how Robertsonian rearrangements can become fixed in a population is not well understood. $M$. gouazoubira populations are an ideal model for clarifying some of these issues. We know that the free-ranging Mazama population located in the Pantanal biome differs in the chromosome number due to Robertsonian rearrangements. In this research, we identified the chromosomes involved in these rearrangements and tested the hypothesis that fusions are the responsible mechanism. We also provide data regarding their potential influence on fertility, fitness, and reproductive isolation of this population.

\section{Materials and Methods}

A major advantage of this research is that all animals studied were wild-caught and the provenience is precisely known. Nineteen ( 12 males and 7 females) free-ranging M. gouazoubira were captured by drive net or darts with transmitters [Duarte et al., 2010] within a $15 \mathrm{~km}$ radius in the Nhecolândia Pantanal in the municipality of Corumbá, Mato Grosso do Sul, Brazil (190 $00^{\prime} 33^{\prime}$ $\left.\mathrm{S}, 57^{\circ} 39^{\prime} 12^{\prime} \mathrm{W}\right)$. Skin biopsies were collected, frozen in liquid nitrogen [Duarte et al., 1999], and later used to obtain chromosomal preparations using fibroblast cultures [Verma and Babu, 1995] which were maintained until passage 4 [Magalhães et al., 2017]. Twenty metaphases of each specimen were analyzed to determine the diploid and fundamental number. G-banding was performed according to Seabright [1971] to correctly identify the chromosomes involved in the rearrangements. The chromosomes were classified as metacentric, submetacentric, or acrocentric by arm ratio [Levan et al., 1964]. B chromosomes were calculated separately of the diploid and fundamental number due to intraindividual variation.

\section{Results}

Among the 19 deer analyzed, 4 different karyomorphs were identified. The most frequent is considered the standard karyotype for the species and presented $2 n=70$,
$\mathrm{FN}=70$, with 68 acrocentric autosomes, an acrocentric $\mathrm{X}$, and a metacentric $\mathrm{Y}$. The other 3 karyomorphs resulted from Robertsonian rearrangements and presented $2 \mathrm{n}=69$ and $\mathrm{FN}=70$ (Fig. 1). If the Robertsonian rearrangements in this population are fusions, the reduction in the diploid number without altering the fundamental number is the result of a centric fusion between various acrocentric chromosomes forming a metacentric or submetacentric chromosome. These 3 karyomorphs differ from each other because of the different chromosomes involved in the fusion.

Of the 19 deer, 5 were carriers of a heterozygous Robertsonian translocation; the chromosomes involved in the rearrangements were identified based on their Gbanding pattern. Among these 5 animals, 3 shared the same karyotype in which the bi-armed chromosome, classified as submetacentric, was the result of Robertsonian translocation between the $\mathrm{X}$ chromosome and autosome 16 (Fig. 1A). The other 2 carriers of the Robertsonian translocation showed bi-armed chromosomes, classified as metacentric. In 1 individual the translocation occurred between chromosomes 4 and 16 (Fig. 1B) and in the other between chromosomes 7 and 21 (Fig. 1C).

Another source of chromosomal polymorphism identified in the population was the inter- and intraindividual variation in dot-like $\mathrm{B}$ chromosomes, with $0-2 \mathrm{~B}$ chromosomes present in addition to the basic complement in 9 individuals of the 19 deer analyzed (Table 1). There was no statistical difference (ANOVA test) in the presence of $\mathrm{B}$ chromosomes between the individuals with a standard karyotype and the carriers of the Robertsonian translocations.

\section{Discussion}

To our knowledge, this is the first cytogenetic study on a population of M. gouazoubira with all analyzed animals caught in the wild in a restricted area. The observed intraspecific chromosomal polymorphisms, such as the presence of $\mathrm{B}$ chromosomes and Robertsonian translocations, have also been reported for other species of the genus Mazama: M. americana [Abril et al., 2010], M. nana [Abril and Duarte, 2008], M. bororo [Duarte and Jorge, 2003], M. nemorivaga [Duarte, 1998], and even for $M$. gouazoubira [Duarte, 1992], though not for such a restricted geographic region. In this work, fibroblast cultures were maintained until passage 4 , and according to Magalhães et al. [2017], M. gouazoubira fibroblast cell lines remain viable and functional until passage 7 . Thus,
148

Cytogenet Genome Res 2018;154:147-152 DOI: $10.1159 / 000488377$
Valeri/Tomazella/Duarte 


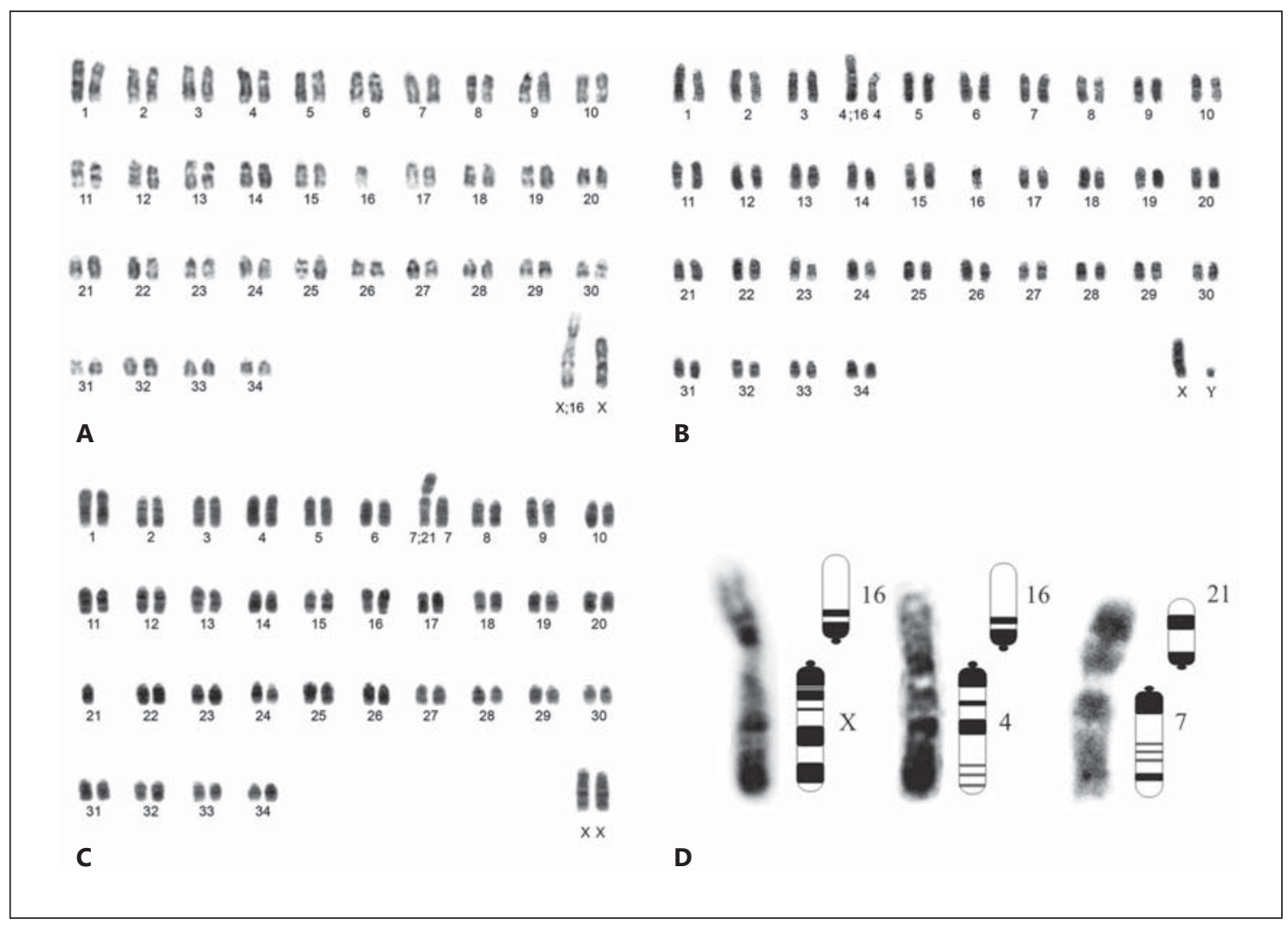

Fig. 1.G-banded karyotypes of M. gouazoubira. A Representative karyotype of the translocation between the X chromosome and autosome 16. B Representative karyotype of the translocation between autosomes 4 and 16 . C Representative karyotype of the translocation between autosomes 7 and 21. D G-banded chromosomes and diagrammatic representation of the respective translocations.

the observed chromosome polymorphism was not related to the number of passages used.

Further, for the first time in M. gouazoubira, we determined which Robertsonian translocations were present within the population using G-banding. Since the chromosomes in this species are all acrocentric and of similar size, except for the Y chromosome (a small metacentric chromosome) [Neitzel, 1987], additional FISH experiments should confirm our results.

All the studies that report Robertsonian translocations in M. gouazoubira conclude centric fusion and not fission as the mechanism responsible for the chromosomal polymorphism, and we tested this hypothesis. The first point is that M. gouazoubira retained the putative ancestral deer karyotype with 70 chromosomes that is standard to the species [Neitzel, 1987; Fontana and Rubini, 1990; Dementyeva et al., 2010]. Five of 19 specimens had $2 n=69$ and maintained $\mathrm{FN}=70$. A mechanism that explains a reduction in the diploid number without changes in the

Intrapopulation Chromosomal Polymorphism in Mazama gouazoubira fundamental number is centric fusion. Also, chromosomal evolution in the Cervidae family is based on centric and tandem fusions, leading to the reduction of the diploid number [Fontana and Rubini, 1990], as observed in the species Muntiacus [Yang et al., 1997], M. americana [Abril et al., 2010], and M. nana [Abril and Duarte, 2008].

In the genus Mazama, chromosomal fragility may facilitate chromosomal breaks and rearrangements and be closely related to intraspecific polymorphisms, chromosomal evolution, and formation of species in the genus following geographic isolation [Vargas-Munar et al., 2010; Tomazella et al., 2017]. The most frequently observed chromosome aberrations in M. gouazoubira by Vargas-Munar et al. [2010] and Tomazella et al. [2017] were chromatid breaks and gaps. According to VargasMunar et al. [2010], M. gouazoubira presents the highest rates of chromosomal aberrations induced by doxorubicin among some deer species (M. nana, M. americana, and Blastocerus dichotomus). Tomazella et al. [2017] 
Table 1. Sex, diploid number (2n), rearranged chromosomes, and number of $\mathrm{B}$ chromosomes in the specimens analyzed

\begin{tabular}{lllll}
\hline Specimen & Sex & 2n & $\begin{array}{l}\text { Robertsonian } \\
\text { rearrangement }\end{array}$ & B chromosomes \\
& & & - & - \\
T128 & m & 70 & - & $0-1$ \\
T155 & m & 70 & - & - \\
T156 & f & 69 & X;16 & $0-1$ \\
T157 & m & 70 & - & - \\
T298 & m & 70 & - & - \\
T299 & f & 70 & - & $0-2$ \\
T300 & m & 69 & X;16 & - \\
T301 & f & 69 & $7 ; 21$ & $0-2$ \\
T302 & m & 69 & $4 ; 16$ & $0-1$ \\
T303 & f & 70 & - & $0-1$ \\
T307 & m & 69 & X;16 \\
T313 & m & 70 & - & - \\
T314 & f & 70 & - & $0-1$ \\
T315 & f & 70 & - & - \\
T316 & m & 70 & - & - \\
T317 & f & 70 & - & - \\
T318 & m & 70 & - & $0-2$ \\
T319 & m & 70 & - & $0-2$ \\
T320 & m & 70 & - & - \\
\hline
\end{tabular}

identified the chromosomes carrying chromosomal aberrations induced by doxorubicin in M. gouazoubira, which could be more prone to chromosomal fragility. The chromosomes with highest frequencies of aberrations were the pairs 1, 2, 4, 5, 6, 7, 15, 16, and X. The chromosomes $\mathrm{X}, 4,7$ and 16 identified in the polymorphism of the Pantanal population have among the highest rates of chromosomal aberrations; their frequencies were 12.41, 9.65, 15.17 , and 9.19\%, respectively. The exception was chromosomal pair 21, which was not reported by Tomazella et al. [2017] as having chromosomal aberrations, but this result may be due to difficulty in identifying this small chromosome.

Neitzel [1987], Fontana and Rubini [1990], and Dementyeva et al. [2010] considered the putative ancestral Cervidae X chromosome as acrocentric. However, Fiorillo et al. [2013] suggest the bi-armed morphology of the $\mathrm{X}$ as the putative ancestral form. Among Mazama species, the $\mathrm{X}$ chromosome presents differences in morphology, being metacentric in M. nana, submetacentric in M. bororo, M. americana, and M. nemorivaga, and is present as an acrocentric chromosome only in M. gouazoubira. These differences are consequences of chromosomal rearrangements such as X-autosomal fusion in M. americana and $M$. nemorivaga and a suggested pericentric in- version in M. gouazoubira. The X differences found in brocket deer could be directly related to the chromosomal fragility observed by Vargas-Munar et al. [2010] and Tomazella et al. [2017]. The tendency of rearrangements observed in Mazama involving the X chromosome agrees with X-autosomal rearrangements found in this work.

In general, rearrangements involving sex-autosome translocations are rare in mammals. However, additionally to the Mazama genus, there are other reports of sexautosome translocations among Cervidae family, including muntjacs (Muntiacus muntjak and M. crinifrons) and the tufted deer (Elaphodus cephalophus) [Wurster and Benirschke, 1970; Shi et al., 1991; Yang et al., 1995; Cao et al., 2005]. This type of chromosomal rearrangement is also described in bats, rodents, bovids, and primates [Ratomponirina et al., 1986; Dobigny et al., 2004; Solari and Rahn, 2005; Noronha et al., 2010; Veyrunes et al., 2014; Vozdova et al., 2016].

Nine of 19 specimens analyzed had B chromosomes; individuals could have no $\mathrm{B}$ chromosomes or up to $2 \mathrm{~B}$ chromosomes. One hypothesis of the origin of B chromosomes is that they result from Robertsonian fusions [Camacho et al., 2000]. If this hypothesis is true, we would expect that B chromosomes in M. gouazoubira should be more frequent in carriers of the Robertsonian translocations. However, we found no statistical difference in the frequency of B chromosomes between animals with Robertsonian fusions and normal karyotypes. Therefore, our data do not support the hypothesis that Robertsonian fusions generate B chromosomes. B chromosomes in $M$. gouazoubira have an important genetic content, since, although they present sequences patterns similar to the autosomal chromosomes, they are composed of 34 complete and 21 partial genes, including the RET and KIT protooncogenes [Makunin et al., 2016].

The centric fusions observed in M. gouazoubira are most likely the result of chromosomal fragility and are usually present in a heterozygous state [Duarte, 1998]. The presence of a heterozygous centric fusion in chromosomes $\mathrm{X}$ and 16, 7 and 21, and 4 and 16 identified in the Pantanal population of M. gouazoubira may be indicative of a recent karyotype evolution and in which the rearrangements are not fixed yet.

In the case of an individual heterozygous for a centric fusion it is thought that this should result in reduced fertility due to segregation and irregular chromosome pairing during meiosis by producing unbalanced gametes [Nachman and Searle, 2012]. However, heterozygotes for a single centric fusion generally form trivalents in meiosis, causing minimal problems in reproduction [Baker
Valeri/Tomazella/Duarte 
and Bickham, 1986], as observed in a meiotic study performed on M. americana [Aquino et al., 2013]. However, Cursino et al. [2014] and Salviano et al. [2017] verified that hybrids of different $M$. americana cytotypes possess a mechanism of post-zygotic reproductive isolation that involves subfertility or infertility, demonstrating reproductive isolation with the accumulation of chromosomal rearrangements.

When accumulated fixation of several centric fusions occurs, reproductive isolation is increasingly likely due to gamete incompatibility [Dobigny et al., 2002]. In isolated populations, centric fusions for different chromosomes are independently fixed, and fertility problems originating in meiosis are minimal. In the case of 2 isolated populations of the same species coming into contact, it is possible that heterozygous individuals for 2 different fusions are produced, and in this case, serious meiotic problems can result in reproductive isolation [Baker and Bickham, 1986]. The population studied here already has at least 3 different types of rearrangements, and they could be present together in some individuals, which theoretically should have a significant negative impact on reproduction.

The reproductive impact is observed when fixation of an $\mathrm{X}$-autosomal rearrangement occurs that can generate a multiple sex chromosome system, $\mathrm{XX} / \mathrm{XY}_{1} \mathrm{Y}_{2}$, leading to reproductive isolation and perhaps future speciation. Within the genus Mazama, the species M. americana and $M$. nemorivaga present a multiple $\mathrm{XX} / \mathrm{XY}_{1} \mathrm{Y}_{2}$ sex chromosome system resulting from $\mathrm{X}$-autosomal fusions [Abril et al., 2010; Fiorillo et al., 2013].

The different rearrangements verified in the population of M. gouazoubira analyzed could be related to the chromosomal fragility previously observed in the genus Mazama [Duarte and Merino, 1997], with the occurrence of frequent mutations that arise and are eliminated within the population due to their effects on fitness and affecting the sustainability of the population. We found centric fusions only in a heterozygous state, probably because of our limited sample, but this could be an indication of a recent occurrence or adaptive advantage of heterozygotes. Banaszek et al. [2009] found higher maximum metabolic rates in heterozygotes for Robertsonian fusions in a common shrew (Sorex araneus) population and suggested it as a selective advantage that could outweigh the expected negative effects of Robertsonian heterozygosity upon fertility, thereby maintaining the polymorphism in this species.

Another hypothesis for the presence of the 3 types of translocations in the area under study is that these rear- rangements exist in other populations and were inserted in the Pantanal population by natural genetic flow. In this case, they might well be eliminated later due to negative effects on fitness.

One interpretation of our results is that the chromosomal data provide evidence of an ongoing process of speciation in Mazama. Therefore, a more robust sampling of the population would offer an opportunity to test some of these hypotheses and provide information on the dynamics of chromosome polymorphisms in populations and their role in speciation.

\section{Acknowledgement}

This study was financially supported by Fundação de Amparo à Pesquisa do Estado de São Paulo (FAPESP, Brazil, grant number 2012/21044-3) and CNPq (grant number 305419/2014-5). The authors are grateful to Roscoe Stanyon for the suggestions and availability in reading this article, all those involved in the field work who were responsible for collecting skin samples, Embrapa Pantanal for logistical support, and all the staff of the Deer Research and Conservation Center (NUPECCE), specially João Boer (lab technician), for their technical support.

\section{Statement of Ethics}

This study was approved by the institutional ethics committee (CEUA - São Paulo State University [Unesp], Permission Number: 000577/13).

\section{Disclosure Statement}

The authors have no conflicts of interest to declare.

References
Abril VV, Duarte JMB: Chromosome polymor-
Mazama nana (Mammalia, Cervidae). Genet
Mol Biol 31:53-57 (2008).
Abril VV, Carnelossi EA, González S, Duarte
JMB: Elucidating the evolution of the red
brocket deer Mazama americana Complex
(Artiodactyla; Cervidae). Cytogenet Genome
Res 128:177-187 (2010).
Aquino CI, Abril VV, Duarte JMB: Meiotic pair-
ing of B chromosomes, multiple sexual sys-
tem, and Robertsonian fusion in the red
brocket deer Mazama americana (Mamma-
lia, Cervidae). Genet Mol Res 12:3566-3574
(2013).
Baker RJ, Bickham JW: Speciation by monobra-
chial centric fusions. Proc Natl Acad Sci USA
83:8245-8248 (1986).

Cytogenet Genome Res 2018;154:147-152 151

Intrapopulation Chromosomal

Polymorphism in Mazama gouazoubira 
- Banaszek A, Taylor JR, Ochocińska D, Chętnicki $\mathrm{W}$ : Robertsonian polymorphism in the common shrew (Sorex araneus L.) and selective advantage of heterozygotes indicated by their higher maximum metabolic rates. Heredity 102:155-162 (2009).

Camacho JPM, Sharbel TF, Beukeboom LW: Bchromosome evolution. Philos Trans R Soc Lond B Biol Sci 355:163-178 (2000).

-Cao X, Jiang H, Zhang X: Polymorphic karyotypes and sex chromosomes in the tufted deer (Elaphodus cephalophus): cytogenetic studies and analyses of sex chromosome-linked genes. Cytogenet Genome Res 109:512-518 (2005).

-Cursino MS, Salviano MB, Abril VV, Zanetti ES, Duarte JMB: The role of chromosome variation in the speciation of the red brocket deer complex: the study of reproductive isolation in females. BMC Evol Biol 14:40-52 (2014).

Daniel A: The Cytogenetics of Mammalian Autosomal Rearrangements, p 921 (A. R. Liss, New York 1988).

- Dementyeva PV, Trifonov VA, Kulemzina AI, Graphodatsky AS: Reconstruction of the putative Cervidae ancestral karyotype by chromosome painting of Siberian roe deer (Capreolus pygargus) with dromedary probes. Cytogenet Genome Res 128:228-235 (2010).

Dobigny G, Aniskin V, Volobouev V: Explosive chromosome evolution and speciation in the gerbil genus Taterillus (Rodentia, Gerbillinae): a case of two new cryptic species. Cytogenet Genome Res 96:117-124 (2002).

Dobigny G, Ozouf-Costaz C, Bonillo C, Volobouev V: Viability of X-autosome translocations in mammals: an epigenomic hypothesis from a rodent case-study. Chromosoma 113: 34-41 (2004).

Duarte JMB: Aspectos Taxonômicos e Citogenéticos de Algumas Espécies de Cervídeos Brasileiros. (Master Dissertation, Faculdade de Ciências Agrárias e Veterinárias, Universidade Estadual Paulista, Jaboticabal 1992).

Duarte JMB: Análise Citogenética e Taxonômica do Gênero Mazama (Cervidae; Artiodactyla) no Brasil. (PhD Thesis, Instituto de Biociências, Universidade Estadual Paulista, Botucatu 1998).

Duarte JMB: Artiodactyla - Cervidae; in Cucas Z, Silva JCR, Catão-Dias JL (eds.): Tratado de Animais Selvagens: Medicina Veterinária, pp 641-664 (Roca, São Paulo 2007).

Duarte JMB, Jorge W: Chromosomal polymorphism in several populations of deer (genus Mazama) from Brazil. Arch Zootec 45:281287 (1996).

Duarte JMB, Jorge W: Morphologic and cytogenetic description of the small red brocket
(Mazama bororo Duarte, 1996) in Brazil. Mammalia 67:403-410 (2003).

Duarte JMB, Merino ML: Taxonomia e evolução; in: Duarte JMB (ed): Biologia e Conservação de Cervídeos Sul-Americanos: Blastocerus, Ozotoceros e Mazama. pp 1-21 (FUNEP, Jaboticabal 1997).

Duarte JMB, Ramalho MFD, Lima VFH, Jorge W: A leukocyte cryopreservation technique for cytogenetic studies. Gen Mol Biol 22:399-400 (1999).

Duarte JMB, Uhart MM, Galvez CES: Capture and physical restraint, in Duarte JMB, González S (eds): Neotropical Cervidology: Biology and Medicine of Latin American Deer, pp 218-227 (IUCN/FUNEP, Gland, Jaboticabal 2010).

Ferlin A, Arredi B, Foresta C: Genetic causes of male infertility. Reprod Toxicol 22:133-141 (2006).

Fiorillo BF, Sarria-Perea JA, Abril VV, Duarte JMB: Cytogenetic description of the Amazonian brown brocket Mazama nemorivaga (Artiodactyla; Cervidae). Comp Cytogenet 7: 25-31 (2013).

-Fontana F, Rubini M: Chromosomal evolution in Cervidae. BioSystems 34:157-174 (1990).

Levan A, Fredga K, Sandberg AA: Nomenclature for centromeric position of chromosomes. Hereditas 52:201-219 (1964).

-Magalhães LC, Bhat MH, Freitas JL, Melo LM, Teixiera DIA, et al: The effects of cryopreservation on different passages of fibroblast cell culture in brown brocket deer (Mazama gouazoubira). Biopreserv Biobank 15:463468 (2017).

Makunin AI, Kichigin IG, Larkin DM, O’Brien PCM, Ferguson-Smith MA, et al: Contrasting origin of B chromosome in two cervids (Siberian roe deer and grey brocket deer) unravelled by chromosome-specific DNA sequencing. BMC Genomics 17:618-632 (2016).

Nachman MW, Searle JB: Why is the house mouse karyotype so variable? Tree 10:397402 (2012).

Neitzel H: Chromosome evolution of Cervidae: karyotypic and molecular aspects, in Obe G, Basler A (eds): Cytogenetics, Basic and Applied Aspects, pp 90-112 (Springer Verlag, Berlin 1987).

Noronha RC, Nagamachi CY, O’Brien PC, Ferguson-Smith MA, Pieczarka JC: Meiotic analysis of XX/XY and neo-XX/XY sex chromosomes in Phyllostomidae by cross-species chromosome painting revealing a common chromosome 15-XY rearrangement in Stenodermatinae. Chromosome Res 18:667-676 (2010).

-Ratomponirina C, Viegas-Pequignot E, Dutrillaux B, Petter F, Rumpler Y: Synaptonemal complexes in Gerbillidae: probable role of intercalated heterochromatin in gonosome-autosome translocations. Cytogenet Genome Res 43:161-167 (1986).

Rodrigues TF, Cerveira JF, Duarte JMB: Uso de áreas agrícolas por Mazama gouazoubira (Mammalia, Cervidae) no Estado de São Paulo. Iheringia Sér Zool 104:439-445 (2014).

- Salviano MB, Cursino MS, Zanetti ES, Abril VV, Duarte JMB: Intraspecific chromosome polymorphisms can lead to reproductive isolation and speciation: an example in red brocket deer (Mazama americana). Biol Reprod 6: 1279-1287 (2017).

Seabright M: A rapid banding technique for human chromosomes. Lancet 1:971-972 (1971).

-Shi L, Yang F, Kumamoto A: The chromosomes of tufted deer (Elaphodus cephalophus). Cytogenet Genome Res 56:189-192 (1991).

- Solari AJ, Rahn MI: Fine structure and meiotic behaviour of the male multiple sex chromosomes in the genus Alouatta. Cytogenet Genome Res 108:262-267 (2005).

Tomazella IM, Abril VV, Duarte JMB: Identifying Mazama gouazoubira (Artiodactyla; Cervidae) chromosomes involved in rearrangements induced by doxorucibin. Genet $\mathrm{Mol}$ Biol 40:460-467 (2017).

- Vargas-Munar DSF, Sarria-Perea JA, Duarte JMB: Different responses to doxorubicin-induced chromosome aberrations in Brazilian deer species. Genet Mol Res 9:1545-1549 (2010).

Verma RS, Babu A: Human Chromosomes: Principles and Techniques, p 419 (McGraw-Hill Inc., New York 1995).

-Veyrunes F, Perez J, Borremans B, Gryseels S, Richards LR, et al: A new cytotype of the African pygmy mouse Mus minutoides in Eastern Africa. Implications for the evolution of sex-autosome translocations. Chromosome Res 22:533-543 (2014).

Vozdova M, Ruiz-Herrera A, Fernandez J, Cernohorska H, Frohlich J, et al: Meiotic behaviour of evolutionary sex-autosome translocations in Bovidae. Chromosome Res 24:325-338 (2016).

- Wurster DH, Benirschke K: Indian muntjac, Muntiacus muntjak: a deer with low diploid chromosome number. Science 168:13641366 (1970).

Yang F, Carter NP, Shi L, Ferguson-Smith MA: A comparative study of karyotypes of muntjacs by chromosome painting. Chromosoma 103: 642-652 (1995).

Y Yang F, O’Brien PCM, Wienberg J, Neitzel H, Lin CC, Ferguson-Smith MA: Chromosomal evolution of the Chinese muntjac (Muntiacus reevesi). Chromosoma 106:37-43 (1997). 